\title{
Modeling, Testing, and Characteristic Analysis of a Planetary Flywheel Inerter
}

\author{
Zheng Ge $(\mathbb{D})$ and Weirui Wang (iD) \\ College of Mechanical Engineering, Zhejiang University, Hangzhou 310027, China \\ Correspondence should be addressed to Weirui Wang; wwrzju@126.com
}

Received 21 May 2017; Accepted 27 December 2017; Published 28 January 2018

Academic Editor: Georges Kouroussis

Copyright ( 2018 Zheng Ge and Weirui Wang. This is an open access article distributed under the Creative Commons Attribution License, which permits unrestricted use, distribution, and reproduction in any medium, provided the original work is properly cited.

\begin{abstract}
We propose the planetary flywheel inerter, which is a new type of ball screw inerter. A planetary flywheel consists of several planetary gears mounted on a flywheel bracket. When the flywheel bracket is driven by a screw and rotating, each planetary gear meshing with an outer ring gear generates a compound motion composed of revolution and rotation. Theoretical analysis shows that the output force of the planetary flywheel inerter is proportional to the relative acceleration of one terminal of the inerter to the other. Optimizing the gear ratio of the planetary gears to the ring gear allows the planetary flywheel to be lighter than its traditional counterpart, without any loss on the inertance. According to the structure of the planetary flywheel inerter, nonlinear factors of the inerter are analyzed, and a nonlinear dynamical model of the inerter is established. Then the parameters in the model are identified and the accuracy of the model is validated by experiment. Theoretical analysis and experimental data show that the dynamical characteristics of a planetary flywheel inerter and those of a traditional flywheel inerter are basically the same. It is concluded that a planetary flywheel can completely replace a traditional flywheel, making the inerter lighter.
\end{abstract}

\section{Introduction}

Mechanical vibration is widely found in nature as well as construction, vehicles, manufacture process, and other engineering fields. For a long time, researchers have deeply carried out studies on how to control the mechanical vibration. The traditional vibration control system is composed of two basic vibration control elements, spring and damper [1].

In 2002, Smith proposed a new type of two-terminal mechanical device called inerter, whose output force is proportional to the relative acceleration of one of the inerter's terminals to the other, as sketched in Figure $1 . x_{1}$ and $x_{2}$ are the two terminals' displacement of the inerter. The proportional coefficient $b$ in the figure is called the inertance and has units of kilograms [2].

$$
F=b\left(\ddot{x}_{1}-\ddot{x}_{2}\right) .
$$

On the one hand, an inerter has two ends, which cannot be implemented by a mass block. On the other hand, the device can convert a linear motion into the rotational motion of a flywheel, which generates much more equivalent inertial mass than the gravitational mass of the flywheel [3]. For example, if the mass block in a dynamic vibration absorber is replaced by an inerter, the overall weight can be reduced by more than $90 \%$ [4]. The two characters of inerters have considerably enriched the design theory of mechanical vibration networks. As the effect of the inerter in the mechanical network is equivalent to that of the capacitor in the electrical network, the theoretical results of the electrical network synthesis can be applied to the mechanical network design. The realization problem of mechanical impedance with inerter was therefore studied in depth [5]. A number of special classes of admittances realization techniques have been applied to vehicle suspension designs [6,7]. Various types of new passive suspension were proposed $[8,9]$. Nowadays, the mechanical network design technology with inerter has also been applied to many fields such as construction [10] and robot [11].

Currently, there are multiple structural variants of inerters, ball screw type [12], rack and pinion type [13], hydraulic motor type [14], fluid type [15, 16], and so on. The ball screw inerter has less friction. And the nut preload of the ball screw 


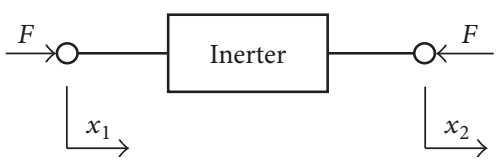

FIGURE 1: Schematic diagram of an inerter.

inerter helps to reduce the impact of the backlash, gaining a better comprehensive performance [17].

Due to the unique advantages of ball screw inerters, the current theoretical research on them is relatively deep. The ball screw has become the structural basis of many new types of inerters. Papageorgiou and Smith established a dynamical model of a ball screw inerter with backslash and nonlinear elastic force and analyzed the influence of nonlinear factors on the dynamical characteristics of the inerter [18]. Hu et al. built a semiactive inerter by adding an electrically adjusted centrifugal block to a ball screw inerter, which provided a method of changing the inertance dynamically [19]. Pires et al. connected a motor to the end of the screw in an inerter and set up the electrical elements at the motor terminals, forming a flexible configuration of electromechanical network [20]. Sun et al. studied the suspension characteristics based on a nonlinear ball screw inerter model, and the parameters of the model were obtained by step-by-step identification of friction parameters and linear parameters [21]. GonzalezBuelga et al. researched the influence of nonlinear factors on the characteristics of tuned inerter damper (TID) and verified the theory by experiments. [22].

The flywheel is the main inertial component of an inerter. An inerter can accomplish dynamical characteristics as a heavy object using a flywheel of small gravitational mass. The greater the ratio of the rotational inertia to the flywheel gravitational mass, the more evident the lightweight effect of the inerter benefits. A traditional flywheel is usually designed as a disk structure. Since the flywheel diameter is normally restricted by the surroundings, the traditional flywheel inertia is largely controlled by and is proportional to the gravitational mass of the flywheel. At present, the research on the flywheel for an inerter is primarily focused on how to dynamically change the inertance by diversification on flywheel structures, which is helpful to control the vibration by active or semiactive method through inerter [19, 23-25]. However, for passive inerter with fixed inertance, there are few designs for lightening the flywheel. In order to further improve the ratio of the rotational inertia to the flywheel gravitational mass (the inertia-to-mass ratio) of the inerter, we propose a planetary flywheel, which utilizes the revolution and rotation of the planetary gears to increase the inertia-tomass ratio.

This paper is organized as follows: Section 2 illustrates the design and a prototype of the planetary flywheel inerter. An ideal model of the new type inerter is established, and the advantages of the planetary flywheel were revealed by comparing it with a traditional flywheel in Section 3. Section 4 analyzes the nonlinear factors of a planetary flywheel and a ball screw inerter, respectively. And then a dynamical model of the planetary flywheel inerter is established. Section 5 focuses on the experimental setup, the model parameter identification, and the model validation. The conclusions are drawn in Section 6.

\section{Design and Prototype Production of a Planetary Flywheel Inerter}

2.1. Introduction of the Design and Principle of the Inerter. As exhibited in Figure 2, the piston rod and the housing are the two moving terminals of the planetary flywheel inerter. The left end of the piston rod is threaded, and the housing has a mounting flange on it for connection. When the relative movement occurs between the two terminals of the inerter, the piston rod moves the nut along the linear bearing and the linear guide rail. The nut then converts the linear motion into the rotary motion of the screw. The flywheel consists of a flywheel bracket and a plurality of planetary gears. The flywheel bracket is fixed at one end of the screw. And the planetary gears are meshed with the ring gear. During the movement, the screw and the flywheel bracket are rotating synchronously. The planetary gears, driven by the flywheel bracket and the ring gear, are governed by a compound motion composed of revolution and rotation.

2.2. Prototype Production. The prototypes of flywheels and an inerter are shown in Figures 3 and 4 . The main structural parameters of the prototype are listed in Table 1.

\section{Ideal Model and Advantages of a Planetary Flywheel Inerter}

3.1. Ideal Model of a Planetary Flywheel Inerter. The inertance $b$ of an ball screw inerter could be calculated using the equation given in [26] as

$$
b=\left(\frac{2 \pi}{P}\right)^{2} J_{\mathrm{e}}
$$

where $J_{\mathrm{e}}$ is the flywheel's rotational inertia.

According to the law of conservation of energy, the torque $T$ of a planetary flywheel satisfies

$$
T \theta_{\mathrm{s}}=\frac{1}{2} J_{\mathrm{s}} \dot{\theta}_{\mathrm{s}}^{2}+N\left(\frac{1}{2} J_{\mathrm{p}} \dot{\theta}_{\mathrm{p}}^{2}+\frac{1}{2} J_{\mathrm{r}} \dot{\theta}_{\mathrm{s}}^{2}\right),
$$

where $J_{\mathrm{s}}=J_{\mathrm{s} 1}+J_{\mathrm{s} 2}$ is the total rotational inertia of the flywheel bracket and the screw, $\theta_{s}$ is the angular displacement of the flywheel about the axis of the screw, and $\theta_{p}$ is the angular displacement of the planetary gear rotation.

Differentiating both sides of (3) yields

$$
T \dot{\theta}_{\mathrm{s}}=J_{\mathrm{s}} \dot{\theta}_{\mathrm{s}} \ddot{\theta}_{\mathrm{s}}+N\left(J_{\mathrm{p}} \dot{\theta}_{\mathrm{p}} \ddot{\theta}_{\mathrm{p}}+J_{\mathrm{r}} \dot{\theta}_{\mathrm{s}} \ddot{\theta}\right) .
$$

In addition, the planetary gears are rotating in accordance with the following relationship:

$$
\begin{aligned}
& \dot{\theta}_{\mathrm{p}}=\left(\frac{Z_{2}-Z_{1}}{Z_{1}}\right) \dot{\theta}_{\mathrm{s}}, \\
& \ddot{\theta}_{\mathrm{p}}=\left(\frac{Z_{2}-Z_{1}}{Z_{1}}\right) \ddot{\theta}_{\mathrm{s}} .
\end{aligned}
$$


TABLE 1: Structural parameters of the prototype.

\begin{tabular}{lcc}
\hline Name & Notation & Specification \\
\hline Modulus of gear & $M_{\text {mod }}$ & 2 \\
Pressure angle of gear & $\alpha$ & $20^{\circ}$ \\
Teeth number of ring gear & $Z_{2}$ & 50 \\
Reference radius of ring gear & $R$ & $0.050 \mathrm{~m}$ \\
Teeth number of planetary gear & $Z_{1}$ & 17 \\
Reference radius of planetary gear & $r$ & $0.017 \mathrm{~m}$ \\
Thickness of planetary gear & $l$ & $0.015 \mathrm{~m}$ \\
Mass of planetary gear & $m_{\mathrm{p}}$ & $0.094 \mathrm{~kg}$ \\
Rotational inertia of rotation of planetary gear & $J_{\mathrm{p}}$ & $1.66 \times 10^{-5} \mathrm{~kg} \cdot \mathrm{m}^{2}$ \\
Rotational inertia of revolution of planetary gear & $J_{\mathrm{r}}$ & $1.02 \times 10^{-4} \mathrm{~kg} \cdot \mathrm{m}^{2}$ \\
Number of planetary gears & $N$ & 4 \\
Radius of pin & $\mathrm{s}$ & $0.0095 \mathrm{~m}$ \\
Thickness of flywheel bracket & $L$ & $0.0075 \mathrm{~m}$ \\
Mass of flywheel bracket (including pins) & $m_{\mathrm{s}}$ & $0.426 \mathrm{~kg}$ \\
Rotational inertia of flywheel bracket (including pins) & $J_{\mathrm{s} 1}$ & $D$ \\
Major diameter of screw & $D$ & $P$ \\
Lead of screw & $P$ & $0.020 \mathrm{~m}$ \\
Rotational inertia of screw & $J_{\mathrm{s} 2}$ & $0.010 \mathrm{~m}$ \\
\hline
\end{tabular}

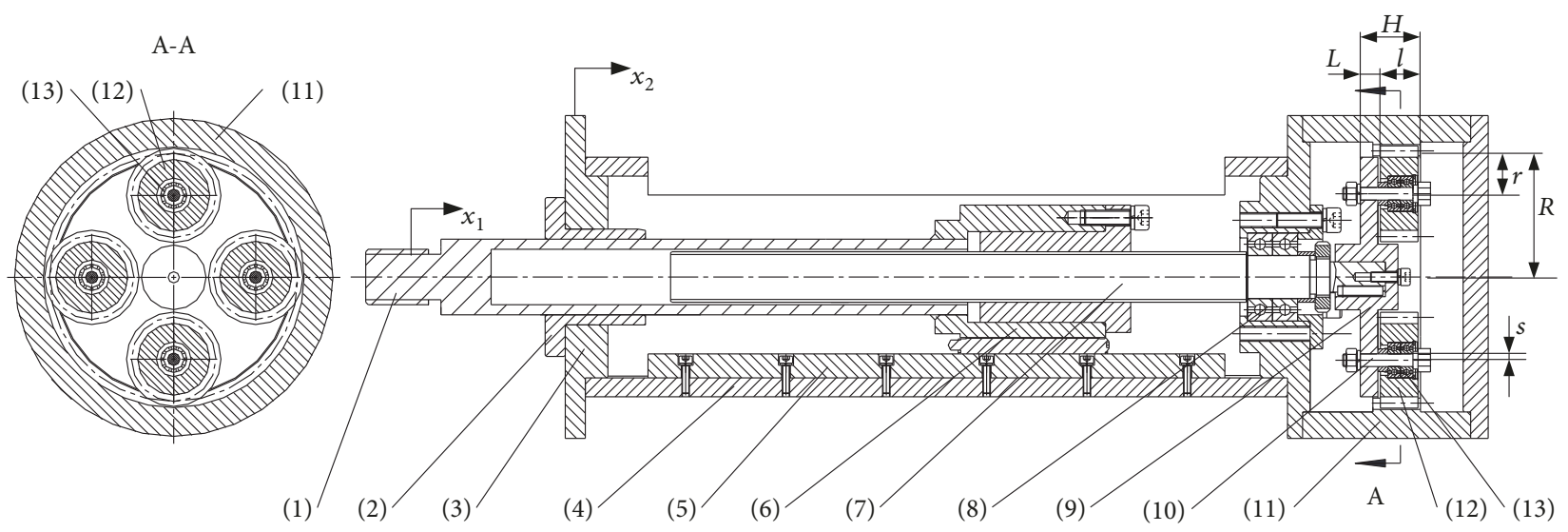

FIGURE 2: Structure of a planetary flywheel inerter: (1) piston rod, (2) linear bearing, (3) mounting flange, (4) housing, (5) linear guide rail, (6) nut, (7) ball screw, (8) screw bearings, (9) flywheel bracket, (10) pin, (11) ring gear, (12) planetary gears, and (13) planetary gear bearings.

Substituting (5) into (4), we get

$$
T=\left\{J_{\mathrm{s}}+N\left[J_{\mathrm{p}}\left(\frac{Z_{2}-Z_{1}}{Z_{1}}\right)^{2}+J_{\mathrm{r}}\right]\right\} \ddot{\theta}_{\mathrm{s}} .
$$

Then the planetary flywheel's rotational inertia could be calculated by

$$
J_{\mathrm{e}}=\frac{T}{\ddot{\theta}_{\mathrm{s}}}=J_{\mathrm{s}}+N\left[J_{\mathrm{p}}\left(\frac{Z_{2}-Z_{1}}{Z_{1}}\right)^{2}+J_{\mathrm{r}}\right] .
$$

Substituting (7) into (2) gives

$$
\begin{aligned}
b & =\left(\frac{2 \pi}{P}\right)^{2} J_{\mathrm{e}} \\
& =\left(\frac{2 \pi}{P}\right)^{2}\left\{J_{\mathrm{s}}+N\left[J_{\mathrm{p}}\left(\frac{Z_{2}-Z_{1}}{Z_{1}}\right)^{2}+J_{\mathrm{r}}\right]\right\} .
\end{aligned}
$$

Equation (8) reveals that the inertance $b$ of a planetary flywheel inerter is directly proportional to the planetary flywheel's rotational inertia $J_{\mathrm{e}}$. With the compound motion of revolution and rotation, the planetary gear's rotational inertia of rotation $J_{\mathrm{p}}$ is added to the inerter's rotational inertia with a gain factor $\left[\left(Z_{2}-Z_{1}\right) / Z_{1}\right]^{2}$. The inerter's rotational inertia is thus conspicuously increased from the traditional case where the mass is the same but is revolving about the axis of the screw only.

By substituting the parameters in Table 1 into (7) and (8), we obtained the rotational inertia to be $9.752 \times 10^{-4} \mathrm{~kg} \cdot \mathrm{m}^{2}$ for the planetary flywheel prototype shown in Figure 3(a) and the inertance to be $385 \mathrm{~kg}$ for the inerter prototype depicted in Figure 4 , where the mass of the planetary flywheel was $m_{\mathrm{pf}}=$ $m_{\mathrm{s}}+4 m_{\mathrm{p}}=0.802 \mathrm{~kg}$. 


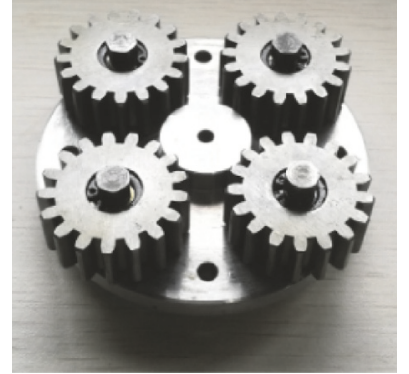

(a)

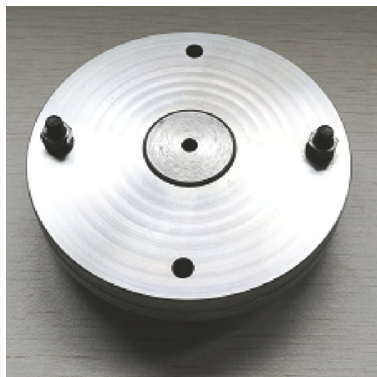

(b)

FIGURE 3: Prototypes of flywheel: (a) planetary flywheel and (b) traditional flywheel.

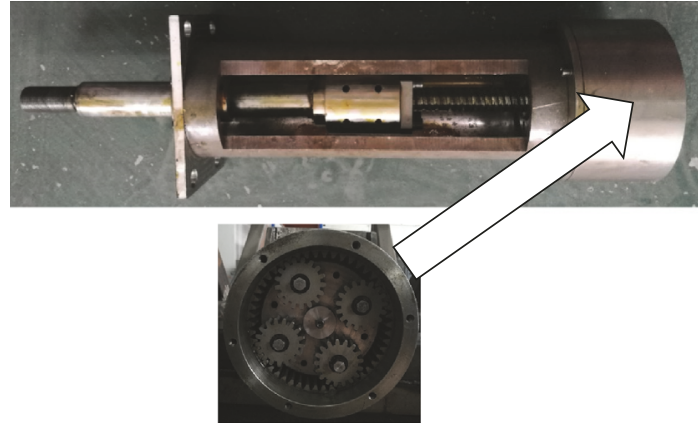

FIgURE 4: Prototype of a planetary flywheel inerter.

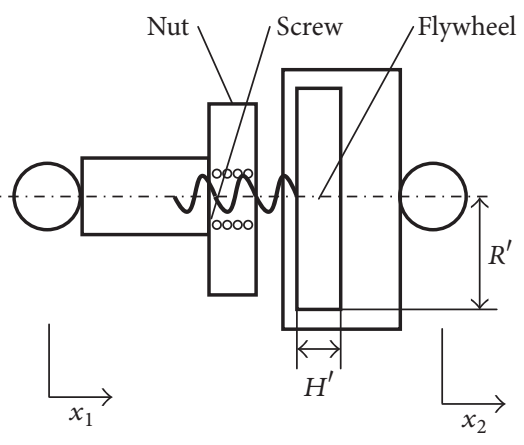

FIgURe 5: Traditional flywheel inerter.
3.2. Advantages of a Planetary Flywheel. As the modulus of the gear is relatively small in terms of the radial scale of the flywheel group, the planetary gears, the flywheel bracket, and the pins are considered homogeneous cylinders. The radius of the planetary flywheel cylinder is approximately equal to the reference circle's radius of the ring gear. The radius of a planetary gear cylinder is approximately equal to the radius of its reference circle. Given that the flywheel bracket and planetary gears are made of identical material with density $\rho$, the mass and the rotational inertia of them are

$$
\begin{aligned}
& m_{\mathrm{s}}=\pi \rho L R^{2}+\pi N \rho l s^{2}, \\
& m_{\mathrm{p}}=\pi \rho l\left(r^{2}-s^{2}\right), \\
& J_{\mathrm{s}}=\pi \rho\left[\frac{1}{2} L R^{4}+N l^{2}(R-r)^{2}\right], \\
& J_{\mathrm{p}}=\frac{1}{2} \pi \rho l\left(r^{2}-s^{2}\right) r^{2}, \\
& J_{\mathrm{r}}=\pi \rho l\left(r^{2}-s^{2}\right)(R-r)^{2} .
\end{aligned}
$$

Substituting (10) into (7) and normalizing the result, the rotational inertia of a planetary flywheel could be rewritten as

$$
J_{\mathrm{e}}=\frac{1}{2} \pi \rho R^{4} L\left[1+N \tau \lambda^{2}\left(3-\beta^{2}\right)(1-\lambda)^{2}\right]
$$

where

$$
\begin{aligned}
& \beta=\frac{s}{r}, \quad 0<\beta<1, \\
& \lambda=\frac{Z_{1}}{Z_{2}}=\frac{r}{R}, \\
& \quad 0<\lambda<\frac{\sin (\pi / N)}{1+\sin (\pi / N)} \text { (Adjacent condition), } \\
& \qquad=\frac{l}{L}, \quad \tau>0 .
\end{aligned}
$$

Then the planetary flywheel's inertia-to-mass ratio $A$ could be determined by

$$
\begin{aligned}
A & =\frac{J_{\mathrm{e}}}{m_{\mathrm{s}}+N m_{\mathrm{p}}} \\
& =\frac{R^{2}}{2}\left\{1+\frac{N \tau \lambda^{2}\left[\left(3-\beta^{2}\right)(1-\lambda)^{2}-1\right]}{1+N \tau \lambda^{2}}\right\} .
\end{aligned}
$$

For the traditional flywheel inerter sketched in Figure 5, its inertia-to-mass ratio $A^{\prime}$ could be calculated by

$$
A^{\prime}=\frac{J_{\mathrm{e}}^{\prime}}{m^{\prime}}=\frac{(1 / 2) \pi \rho H^{\prime} R^{\prime 4}}{\pi \rho H^{\prime} R^{\prime 2}}=\frac{R^{\prime 2}}{2} .
$$

Equation (14) indicates that the inertia-to-mass ratio of a traditional inerter is determined by the radial size of the 


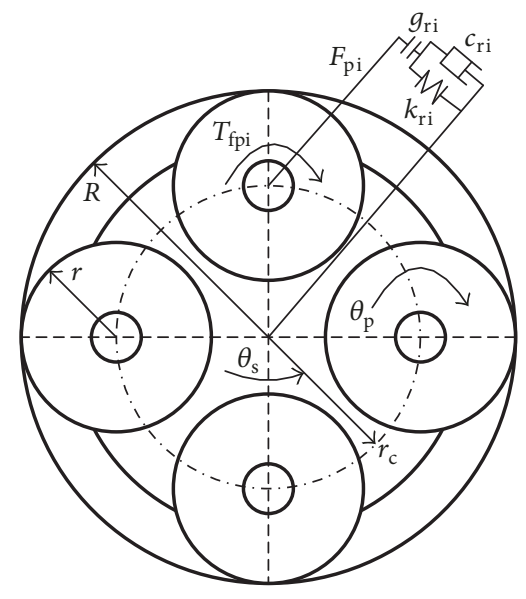

FIGURE 6: Schematic dynamical model of planetary flywheel.

flywheel $R^{\prime}$ and is independent of the flywheel thickness. A larger inertia-to-mass ratio can be accomplished only by a larger flywheel radial dimension.

According to (13) and (14), given that the two types of flywheels share the identical radial size, the ratio between the two flywheels' inertia-to-mass ratios is

$$
\frac{A}{A^{\prime}}=1+\frac{N \tau \lambda^{2}\left[\left(3-\beta^{2}\right)(1-\lambda)^{2}-1\right]}{1+N \tau \lambda^{2}} .
$$

It can be deduced from (15) that when $\lambda<1-1 / \sqrt{3-\beta^{2}}$, there are $\left(3-\beta^{2}\right)(1-\lambda)^{2}-1>0$ and $A>A^{\prime}$. That is, given the gear ratio $\lambda$ of the planetary gear to the ring gear being less than a certain value, the planetary flywheel's inertia amplification capacity is greater than that of the traditional flywheel.

As a reference, a prototype of the traditional flywheel was produced as shown in the Figure 3(b), which has a diameter of $100 \mathrm{~mm}$, same as the diameter of the planetary flywheel prototype. The mass of the traditional flywheel was $0.974 \mathrm{~kg}$, and the rotational inertia was $9.752 \times 10^{-4} \mathrm{~kg} \cdot \mathrm{m}^{2}$. Given that the traditional flywheel is installed to the end of the screw, the inertance of the inerter was $385 \mathrm{~kg}$, equal to that of the planetary flywheel inerter.

Therefore, the mass of the planetary flywheel was $17.7 \%$ less than that of the traditional flywheel while keeping the flywheel diameters as well as the inerter inertances the same. The weight of the inerter was reduced significantly.

\section{Dynamical Model of a Planetary Flywheel Inerter}

4.1. Dynamical Model of a Planetary Flywheel. Given that all the gears are standard cylindrical spur gears and the planetary gears have the same physical and geometric parameters, the concentrated mass method given in [27] was used to establish a planetary flywheel dynamical model, which is shown in Figure 6.

Where $r_{\mathrm{c}}=R-r$ is the center distance between the planetary gear and the ring gear, $i=1,2, \ldots, N, k_{\mathrm{ri}}$ is the meshing stiffness of the meshing gear pair along the line of action, $c_{\mathrm{ri}}$ is the meshing damping coefficient of the gear pair, $g_{\mathrm{ri}}$ indicates the gear backslash, $F_{\mathrm{pi}}$ is the meshing force between the planetary gear and the ring gear, and $T_{\mathrm{fpi}}$ is the equivalent friction torque of the planetary gear about its rotation axis.

Lagrange's equation was used to derive the differential equation governing the dynamical planetary flywheel system as follows:

$$
\begin{gathered}
J_{\mathrm{p}} \ddot{\theta}_{\mathrm{pi}}=F_{\mathrm{pi}} r_{\mathrm{b}}-T_{\mathrm{fpi}}, \\
\left(J_{\mathrm{s}}+N J_{\mathrm{r}}\right) \ddot{\theta}_{\mathrm{s}}=T_{\mathrm{a}}-\sum_{i=1}^{N} F_{\mathrm{pi}} r_{\mathrm{c}} \cos \alpha,
\end{gathered}
$$

where $r_{\mathrm{b}}$ is the radius of the planetary gear's base circle and $T_{\mathrm{a}}$ is the total torque of the planetary flywheel.

The generalized coordinates and the equivalent mass of gears could be defined as

$$
\begin{aligned}
& x_{\mathrm{pi}}=\theta_{\mathrm{pi}} r_{\mathrm{b}}, \\
& x_{\mathrm{s}}=\theta_{\mathrm{s}} r_{\mathrm{c}} \cos \alpha, \\
& m_{\mathrm{pe}}=\frac{J_{\mathrm{p}}}{r_{\mathrm{b}}^{2}}, \\
& m_{\mathrm{re}}=\frac{J_{\mathrm{r}}}{r_{\mathrm{c}}^{2} \cos ^{2} \alpha}, \\
& m_{\mathrm{se}}=\frac{J_{\mathrm{s}}}{r_{\mathrm{c}}^{2} \cos ^{2} \alpha} .
\end{aligned}
$$

Substituting (17) into (16), we get

$$
\begin{gathered}
m_{\mathrm{pe}} \ddot{x}_{\mathrm{pi}}=F_{\mathrm{pi}}-\frac{T_{\mathrm{fpi}}}{r_{\mathrm{b}}}, \\
\left(m_{\mathrm{se}}+N m_{\mathrm{re}}\right) \ddot{x}_{\mathrm{s}}=\frac{T_{\mathrm{a}}}{r_{\mathrm{c}} \cos \alpha}-\sum_{i=1}^{N} F_{\mathrm{pi}} .
\end{gathered}
$$

The elastic meshing force $P_{\mathrm{i}}$ and the viscous meshing force $D_{\mathrm{i}}$ of the gear pair could be expressed as

$$
\begin{gathered}
P_{\mathrm{i}}=k_{\mathrm{ri}}\left(x_{\mathrm{s}}-x_{\mathrm{pi}}\right), \\
D_{\mathrm{i}}=c_{\mathrm{ri}}\left(\dot{x}_{\mathrm{s}}-\dot{x}_{\mathrm{pi}}\right) .
\end{gathered}
$$

The meshing force $F_{\mathrm{pi}}$ could be written using the mechanical clearance model given in [28] as

$$
F_{\mathrm{pi}}= \begin{cases}k_{\mathrm{ri}}\left(x_{\mathrm{s}}-x_{\mathrm{pi}}-g_{\mathrm{ri}}\right)+D_{\mathrm{i}} & P_{\mathrm{i}}+D_{\mathrm{i}} \geq k_{\mathrm{ri}} g_{\mathrm{ri}} \\ 0 & \left|P_{\mathrm{i}}+D_{\mathrm{i}}\right|<k_{\mathrm{ri}} g_{\mathrm{ri}} \\ k_{\mathrm{ri}}\left(x_{\mathrm{s}}-x_{\mathrm{pi}}+g_{\mathrm{ri}}\right)+D_{\mathrm{i}} & P_{\mathrm{i}}+D_{\mathrm{i}} \leq-k_{\mathrm{ri}} g_{\mathrm{ri}} .\end{cases}
$$

Using the Coulomb viscous friction model, the equivalent friction torque of the planetary wheel about the rotation axis $T_{\text {fpi }}$ is

$$
T_{\text {fpi }}=T_{\text {fpm }} \operatorname{sgn}\left(\dot{\theta}_{\mathrm{pi}}\right)+T_{\mathrm{fpv}} \dot{\theta}_{\mathrm{pi}},
$$




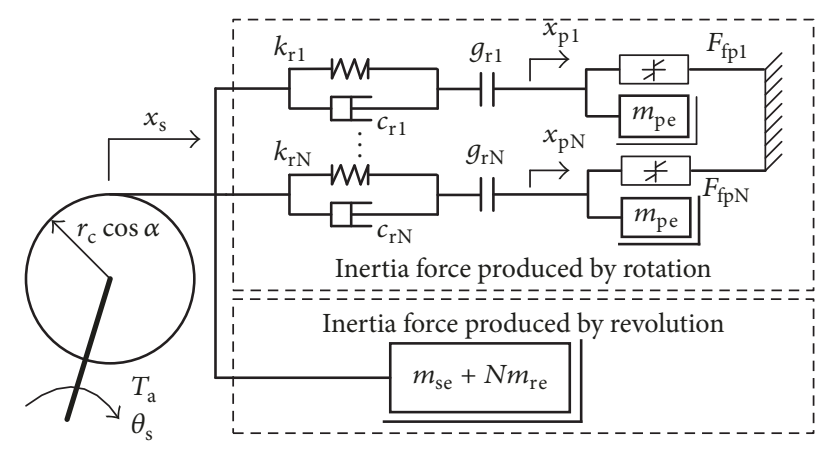

FIGURE 7: Dynamical model of a planetary flywheel.

where $T_{\mathrm{fpm}}$ is the Coulomb friction torque of the planetary wheel about the rotation axis; $T_{\mathrm{fpv}}$ is the viscous friction torque coefficient of the planetary wheel about the rotation axis.

According to (18)-(21), a dynamical model of the planetary flywheel is shown in Figure 7 , where $F_{\mathrm{fpi}}=T_{\mathrm{fpi}} / r_{\mathrm{b}}$. The torque of the planetary flywheel is generated by the revolution and rotation of the gears.

4.2. Dynamical Model of a Ball Screw Type Inerter. A traditional flywheel ball screw inerter model with nonlinear factors such as clearance and friction is presented in [3]. Given the traditional flywheel being replaced by a planetary flywheel, the mechanical principle of the planetary flywheel inerter is shown in Figure 8.

Where $k_{\mathrm{s}}$ is the axial stiffness of the nut-screw pair, $c_{\mathrm{s}}$ is the axial damping coefficient of the nut-screw pair, $\varepsilon_{1}$ is the axial backslash between the nut and the screw, $\varepsilon_{2}$ is the axial internal clearance of the bearing, $m_{\mathrm{r}}$ is the mass of the nut and the piston rod, $x_{3}$ is the axial displacement of the screw, $F_{\mathrm{d}}$ is the axial driving force applied to the screw by the nut, $T_{\mathrm{a}}$ is the torque transmitted to the flywheel by the screw, $T_{\mathrm{f} 1}$ is the friction torque between the nut and the screw, and $T_{\mathrm{f} 2}$ is the bearing friction torque.

The output force $F$ of the inerter and the forces applied on the piston rod and the nut satisfy

$$
F=F_{1}-F_{2}=F_{\mathrm{d}}+m_{\mathrm{r}} \ddot{x}_{1} .
$$

The axial elastic force $P_{\mathrm{i}}$ and the axial viscous force $D_{\mathrm{i}}$ applied upon the nut-screw system could be given as

$$
\begin{aligned}
& P_{\mathrm{s}}=k_{\mathrm{s}}\left(x_{1}-x_{3}\right), \\
& D_{\mathrm{s}}=c_{\mathrm{s}}\left(\dot{x}_{1}-\dot{x}_{3}\right) .
\end{aligned}
$$

Let $\varepsilon=\varepsilon_{1}+\varepsilon_{2} ; F_{\mathrm{d}}$ could be written as

$$
F_{\mathrm{d}}= \begin{cases}k_{\mathrm{s}}\left(x_{1}-x_{3}-\varepsilon\right)+D_{\mathrm{s}} & P_{\mathrm{s}}+D_{\mathrm{s}} \geq k_{\mathrm{s}} \varepsilon \\ 0 & \left|P_{\mathrm{s}}+D_{\mathrm{s}}\right|<k_{\mathrm{s}} \varepsilon \\ k_{\mathrm{s}}\left(x_{1}-x_{3}+\varepsilon\right)+D_{\mathrm{s}} & P_{\mathrm{s}}+D_{\mathrm{s}} \geq-k_{\mathrm{s}} \varepsilon\end{cases}
$$

The torque applied to the flywheel by the screw is

$$
T_{\mathrm{a}}=T_{\mathrm{d}}-T_{\mathrm{f}}
$$

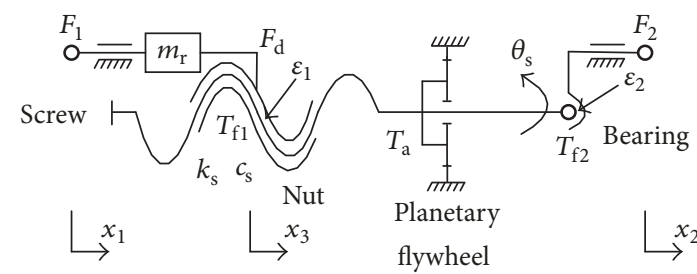

FIGURE 8: Mechanical scheme of a ball screw type inerter with planetary flywheel.

where $T_{\mathrm{d}}$ is the driving torque generated by the nut-screw pair and $T_{\mathrm{f}}=T_{\mathrm{f} 1}+T_{\mathrm{f} 2}$ is the total friction torque of the nut-screw pair and the bearing. Using the Stribeck friction model given in [29], the friction torque $T_{\mathrm{f}}$ can be expressed as

$$
T_{\mathrm{f}}=\left[T_{\mathrm{c}}+\left(T_{\mathrm{s}}-T_{\mathrm{c}}\right) e^{-\left|\dot{\theta}_{\mathrm{s}}\right| / \dot{\theta}_{\text {stribeck }}}\right] \operatorname{sgn}\left(\dot{\theta}_{\mathrm{s}}\right)+T_{\mathrm{v}} \dot{\theta}_{\mathrm{s}},
$$

where $T_{\mathrm{c}}$ is the total Coulomb friction torque of the nut-screw pair and the bearing; $T_{\mathrm{s}}$ is the total static friction torque; $\dot{\theta}_{\text {stribeck }}$ is the Stribeck velocity; $T_{\mathrm{v}}$ is the viscous friction torque coefficient.

By the principle of nut-screw pair, the relationship between the axial forces and their corresponding torques is

$$
\begin{aligned}
& F_{\mathrm{d}}=\frac{2 \pi}{P} T_{\mathrm{d}}, \\
& F_{\mathrm{f}}=\frac{2 \pi}{P} T_{\mathrm{f}}, \\
& F_{\mathrm{a}}=\frac{2 \pi}{P} T_{\mathrm{a}} .
\end{aligned}
$$

Based on the dynamical model of a planetary flywheel established in Section 4.1 and (22) (27), a comprehensive dynamical model of a planetary flywheel inerter is presented in Figure 9, where $\theta_{\mathrm{s}}=(2 \pi / P)\left(x_{3}-x_{2}\right)$.

\section{Experiment}

5.1. Test-Rig Setup. As shown in Figures 10 and 11, the inerter was mounted on the test-rig frame through the mounting flange. The hydraulic actuator's output rod was fixed to the piston rod through the connector. The hydraulic actuator was controlled by a $\operatorname{Moog}^{\mathrm{TM}}$ portable controller to create a relative movement between the flange end and the piston rod end of the inerter. The NI Compact-RIO ${ }^{\mathrm{TM}}$ data acquisition system was deployed to collect the displacement and force data of the inerter with sampling frequency of $1000 \mathrm{~Hz}$ and send it to the PC system for subsequent data analysis.

5.2. Parameter Identification and Model Validation. In order to reduce the computational complexity of the parameter identification process, the parameter identification was carried out stepwise. Firstly, no flywheel was attached to the inerter. The frictional parameters of the inerter were identified. Next, a traditional flywheel was mounted on the inerter and the dynamical parameters of the ball screw were identified. Then, the traditional flywheel was replaced with 


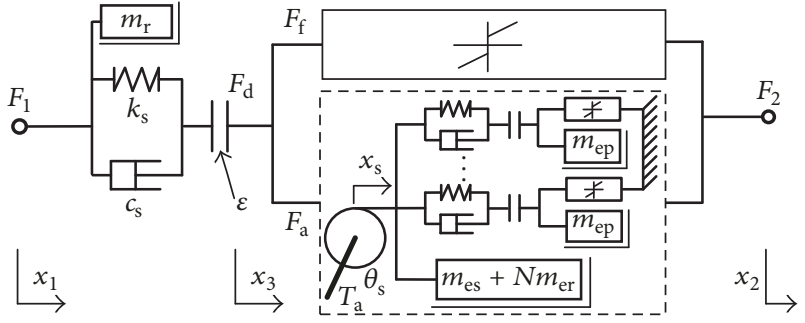

FIGURE 9: Dynamical model of a planetary flywheel inerter.

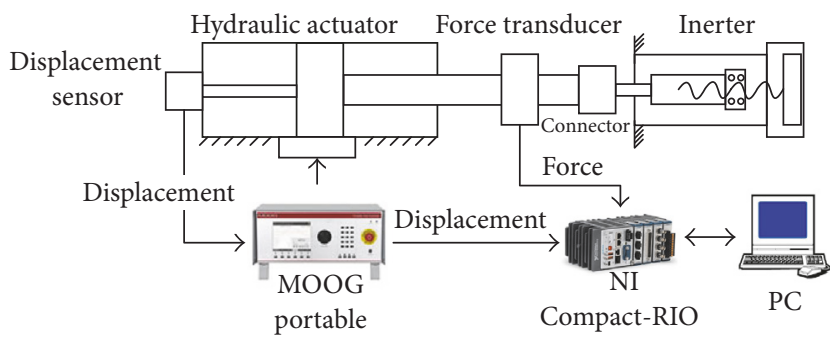

Figure 10: Scheme of the test-rig.

the planetary flywheel. And the dynamical parameters of the planetary flywheel were identified. Finally, the determined parameters were substituted into the model, and the accuracy of the model was validated by various experiments. The model was solved using the MATLAB ${ }^{\mathrm{TM}}$ software with the ode45 solver for both the parameter identification and the model validation.

5.2.1. Frictional Parameters of the Ball Screw Type Inerter. During the experiment phase for the frictional parameter identification, no flywheel was fixed to the inerter. The hydraulic actuator drove the piston rod in a sinusoidal style with amplitude of $20 \mathrm{~mm}$ and a frequency of $0.1 \mathrm{~Hz}$. At this time, the frequency of motion was very low, the relative velocity and acceleration of one terminal to the other of the inerter were small, and the damping and inertia effect could be ignored. The output force of the inerter was basically due to friction.

In the experiment, the output force data of the inerter prototype $F_{\text {exp }}$ was collected. A population of candidate frictional parameter solutions was given to the Stribeck friction model described by (26) and (27). The resulting model output forces $F_{\text {mod }}=F_{\mathrm{f}}$ were then compared with the target $F_{\text {exp }}$ using the following loss function:

$$
\min \left\|F_{\text {exp }}(t)-F_{\text {mod }}\left(T_{\mathrm{c}}, T_{\mathrm{s}}, \dot{\theta}_{\mathrm{s}}, T_{\mathrm{v}}\right)\right\|_{2}^{2} .
$$

$F_{\text {exp }}$ and $F_{\text {mod }}$ were both filtered by a 6-order low-pass Butterworth filter with a cutoff frequency of $0.5 \mathrm{~Hz}$. As a result, the Stribeck friction model parameters of the overall ball screw type inerter were estimated and listed in Table 2.

As shown in Figure 12, given the identified inerter's frictional parameters listed in Table 2, the model could basically describe the friction characteristics of the ball screw type inerter.
TABLE 2: Frictional parameters of the ball screw type inerter.

\begin{tabular}{lc}
\hline Parameter & Specification \\
\hline$T_{\mathrm{c}}$ & $1.975 \times 10^{-1} \mathrm{~N} \cdot \mathrm{m}$ \\
$T_{\mathrm{s}}$ & $2.231 \times 10^{-1} \mathrm{~N} \cdot \mathrm{m}$ \\
$\dot{\theta}_{\text {stribeck }}$ & $5.437 \times 10^{8} \mathrm{rad} / \mathrm{s}$ \\
$T_{\mathrm{v}}$ & $2.703 \times 10^{-3} \mathrm{~N} \cdot \mathrm{m} \cdot \mathrm{s} / \mathrm{rad}$ \\
\hline
\end{tabular}

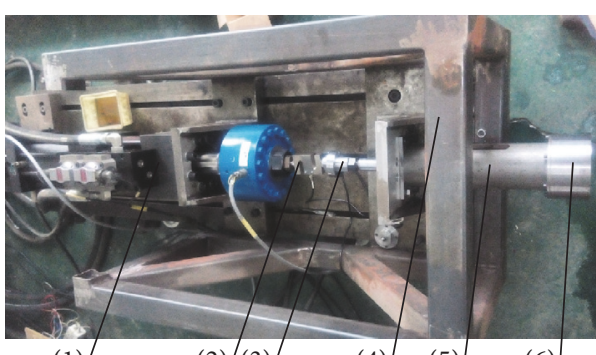

(1)

$(2)(3)$

(4) (5)

(6)

FIgure 11: Prototype of the inerter and the test-rig: (1) hydraulic actuator, (2) force transducer, (3) connector, (4) test-rig frame, (5) inerter, and (6) flywheel chamber.

5.2.2. Parameters of the Ball Screw. The traditional flywheel shown in Figure 3(b) was installed at the end of the screw. The purpose of the flywheel was to amplify the magnitude of output for improving the measurement accuracy. The hydraulic actuator drove the piston rod in a sinusoidal style with amplitude of $10 \mathrm{~mm}$ and a frequency of $3 \mathrm{~Hz}$.

With the inerter's frictional parameters given in Table 2, a population of candidate dynamical parameter solutions of the ball screw were set to the model of the traditional flywheel inerter described in the literature [3]. The resulting model output forces $F_{\text {mod }}$ were then compared with the target $F_{\exp }$ using the following loss function:

$$
\min \left\|F_{\exp }(t)-F_{\text {mod }}\left(m_{\mathrm{r}}, b, k_{\mathrm{s}}, c_{\mathrm{s}}, \varepsilon\right)\right\|_{2}^{2} .
$$

As a result, the parameters of the ball screw were estimated and listed in Table 3.

As displayed in Figure 13, given that the identified inerter's frictional parameters and the ball screw's dynamical ones are shown in Table 3, the model output force agreed well with the experiment data.

5.2.3. Parameters of the Planetary Flywheel. The traditional flywheel was then replaced with the planetary flywheel shown in Figure 3(a). The hydraulic actuator drove the piston rod in a sinusoidal style with amplitude of $10 \mathrm{~mm}$ and a frequency of $3 \mathrm{~Hz}$.

Since the four planetary gears were manufactured together, their mutual difference was considered ignorable. It was assumed that their meshing stiffness, meshing damping coefficient, backslash, and friction torque were the same, respectively.

With the inerter's frictional parameters given in Table 2 and the parameters of the ball screw given in Table 3, a population of candidate planetary flywheel parameter solutions were assigned to the model of planetary flywheel inerter 
TABLE 3: Parameters of the ball screw.

\begin{tabular}{lc}
\hline Parameter & Specification \\
\hline$m_{\mathrm{r}}$ & $1.701 \mathrm{~kg}$ \\
$k_{\mathrm{s}}$ & $1.168 \times 10^{7} \mathrm{~N} / \mathrm{m}$ \\
$c_{\mathrm{s}}$ & $1.223 \times 10^{3} \mathrm{~N} \cdot \mathrm{s} / \mathrm{m}$ \\
$\varepsilon$ & $1.006 \times 10^{-7} \mathrm{~m}$ \\
\hline
\end{tabular}

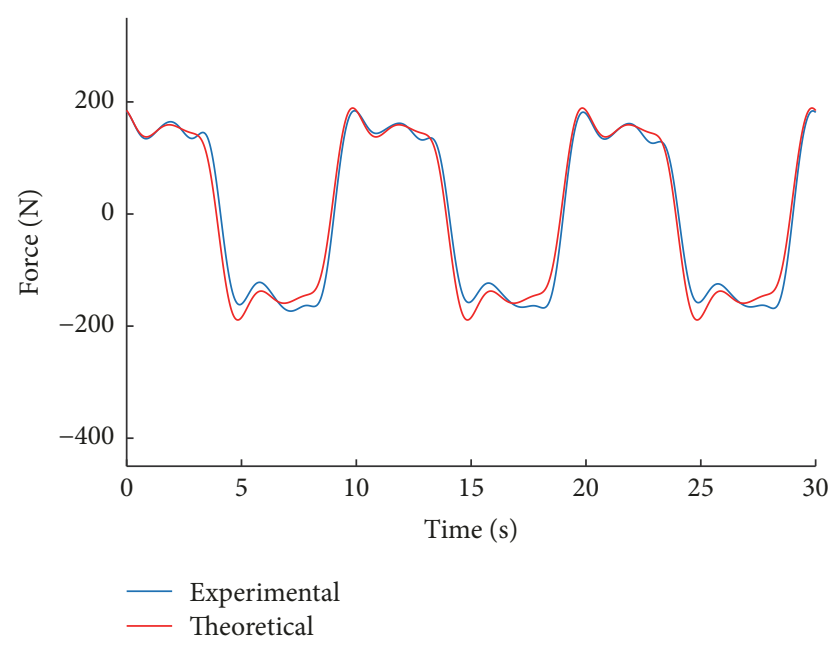

FIGURE 12: Low-frequency response of the ball screw type inerter: displacement input amplitude $=20 \mathrm{~mm}$ and frequency $=0.1 \mathrm{~Hz}$.

shown in Figure 9. The resulting model output forces $F_{\text {mod }}=$ $F_{1}-F_{2}$ were then compared with the target $F_{\text {exp }}$ using the following loss function:

$$
\min \left\|F_{\text {exp }}(t)-F_{\text {mod }}\left(k_{\mathrm{r}}, c_{\mathrm{r}}, g_{\mathrm{r}}, T_{\mathrm{pm}}, T_{\mathrm{pv}}\right)\right\|_{2}^{2} .
$$

As a result, the parameters of the planetary flywheel were estimated and listed in Table 4.

As illustrated in Figure 14(b), the model output force agreed well with the experiment data as all the identified parameters listed in Table 4 are given.

5.2.4. Validation of the Dynamical Model. With all the key parameters of the planetary flywheel inerter determined, the frictional parameters, the parameters of the ball screw, and the planetary flywheel parameters were substituted into the inerter model shown in Figure 9. Then, by inputting the sinusoidal displacement excitation of different frequencies to the inerter, the feasibility of the model was tested by comparing the experiment data with the model output.

Figures 14(a), 14(c), and 14(d) demonstrate that the output of the model agreed well with the output of the experimental inerter under the excitation of three frequencies (low frequency: frequency $=0.1 \mathrm{~Hz}$ and amplitude $=$ $20 \mathrm{~mm} ; F_{\text {exp }}$ and $F_{\text {mod }}$ were both filtered by a 6 -order lowpass Butterworth filter with a cutoff frequency of $0.5 \mathrm{~Hz}$; intermediate frequency: frequency $=5 \mathrm{~Hz}$ and amplitude $=$ $7 \mathrm{~mm}$; high frequency: frequency $=10 \mathrm{~Hz}$ and amplitude $=$ $1.5 \mathrm{~mm}$ ). Experiments showed an outstanding accuracy of the theoretical dynamical model.
TABLE 4: Parameters of the planetary flywheel.

\begin{tabular}{lc}
\hline Parameter & Specification \\
\hline$k_{\mathrm{r}}$ & $1.353 \times 10^{9} \mathrm{~N} / \mathrm{m}$ \\
$c_{\mathrm{r}}$ & $4.671 \times 10^{4} \mathrm{~N} \cdot \mathrm{s} / \mathrm{m}$ \\
$g_{\mathrm{r}}$ & $1.838 \times 10^{-6} \mathrm{~mm}$ \\
$T_{\mathrm{pm}}$ & $8.067 \times 10^{-4} \mathrm{~N} \cdot \mathrm{m}$ \\
$T_{\mathrm{pv}}$ & $1.366 \times 10^{-4} \mathrm{~N} \cdot \mathrm{m} \cdot \mathrm{s} / \mathrm{rad}$ \\
\hline
\end{tabular}

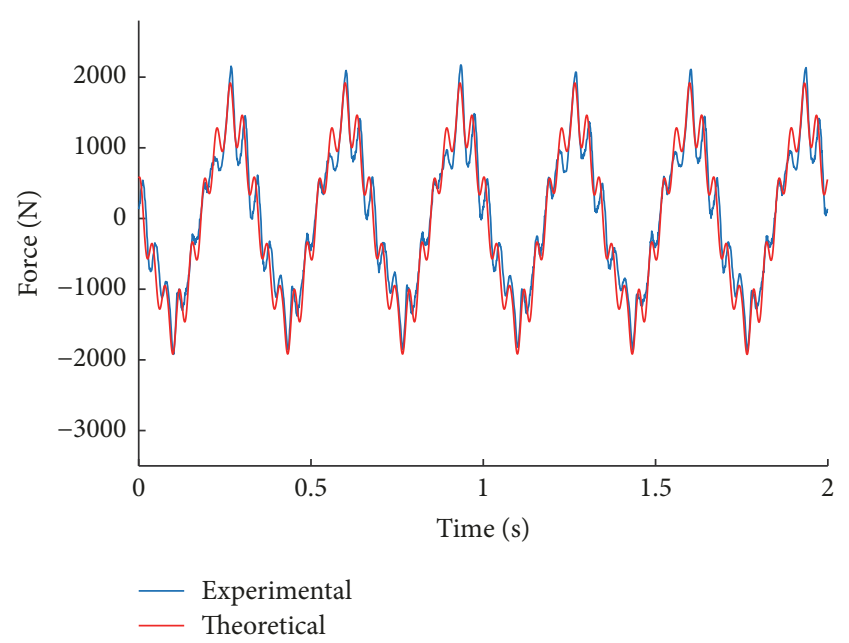

FIGURE 13: Time response of the traditional flywheel inerter: displacement input amplitude $=10 \mathrm{~mm}$ and frequency $=3 \mathrm{~Hz}$.

5.3. Random Input Test and Transfer Characteristics Analysis. To reveal the transfer characteristics of the inerter in the frequency domain, a white noise speed excitation of a range of $0.5 \sim 15 \mathrm{~Hz}$ as shown in Figure 15 was applied to the planetary flywheel inerter and its traditional flywheel counterpart by the hydraulic actuator. The power spectral density of input was

$$
G_{\text {input }}(f)=6.4 \times 10^{-6} \cdot f^{-2}\left(\mathrm{~m}^{2} / \mathrm{Hz}\right) .
$$

The transfer characteristics of an inerter is defined as

$$
H(f)=\frac{G_{\text {in-out }}(f)}{G_{\text {input }}(f)},
$$

where $G_{\text {in-out }}(f)$ is the cross power spectral density of the input displacement and the output force.

From Figure 16, the transfer characteristics of the planetary flywheel inerter are similar to that of the traditional flywheel inerter with the same inertance. In the lower frequency band, the amplitude gain of the planetary flywheel inerter is slightly larger than that of the traditional flywheel counterpart, as a result of the introduction of the planetary gears' friction to the former one. In the higher frequency band above $2 \mathrm{~Hz}$, the transfer characteristics of the two types of inerter are basically the same, and both increase with a higher frequency, in line with the characteristics of an ideal inerter.

Moreover, the transfer characteristics of the dynamical model were in good agreement with the experimental results at a relatively high frequency, which further validates the 


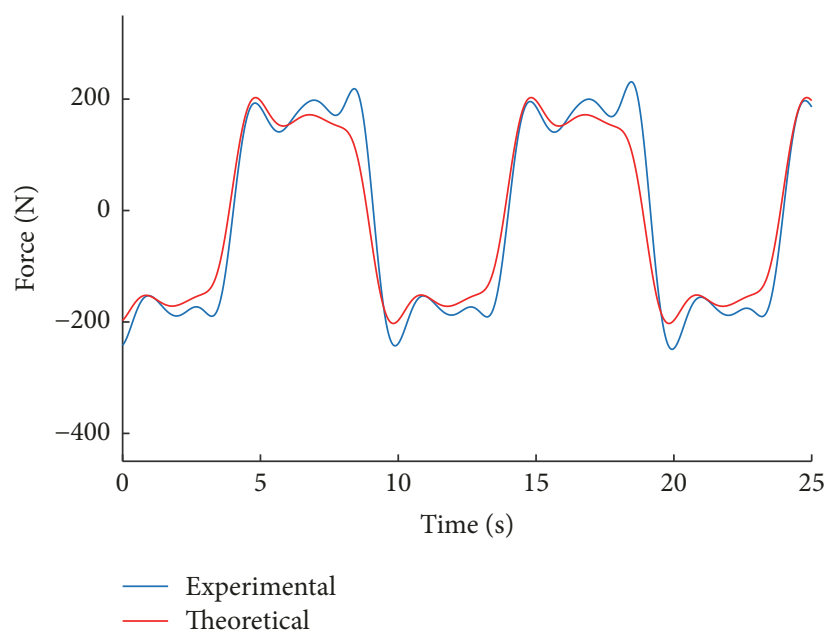

(a)

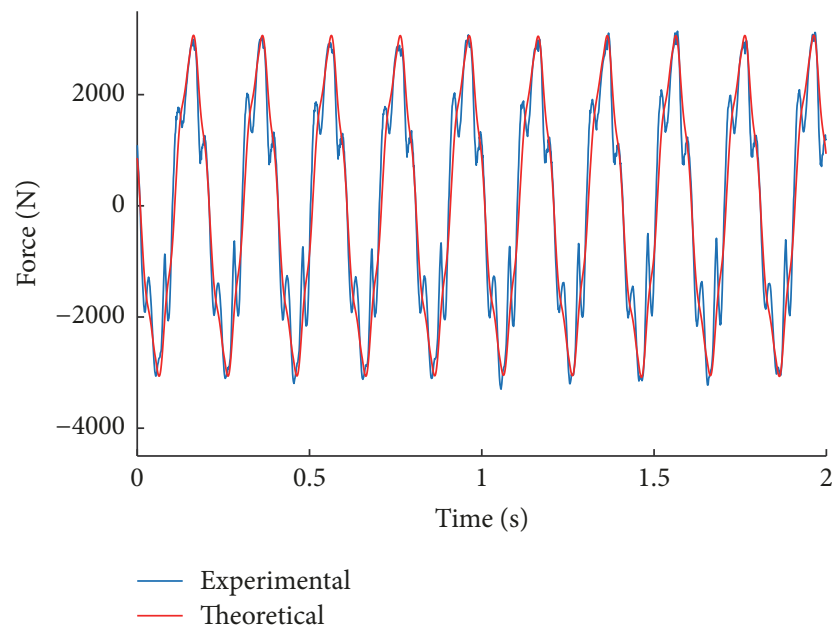

(c)

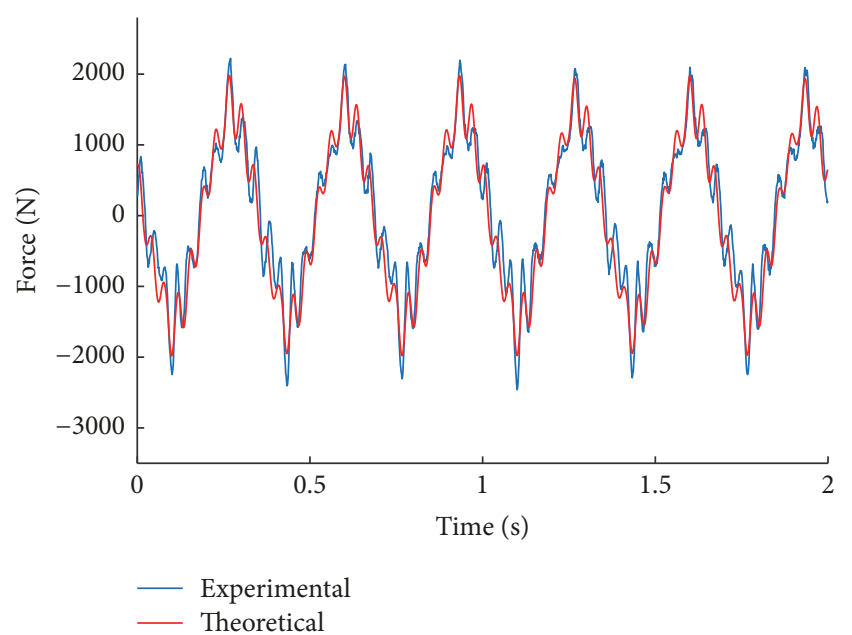

(b)

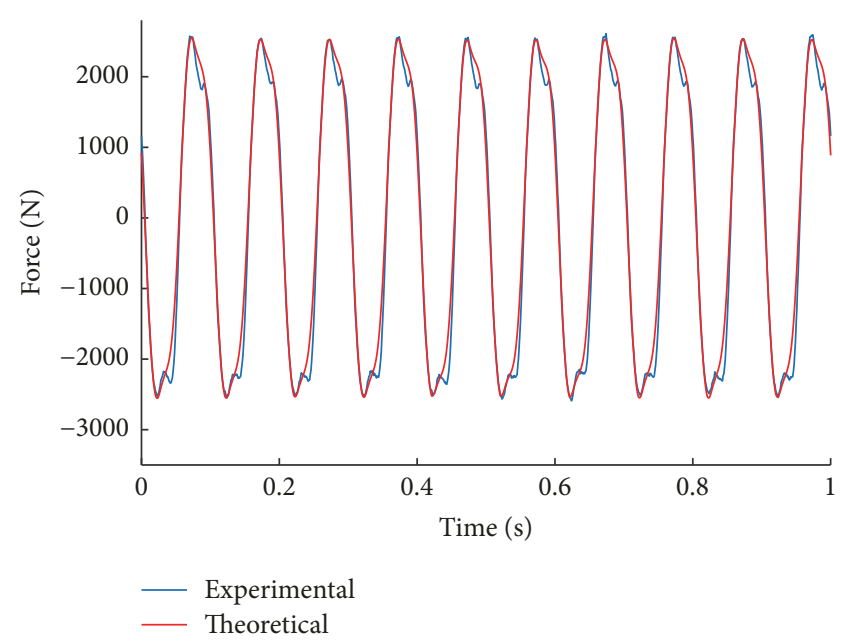

(d)

FIGURE 14: Time response of the inerter with planetary flywheel: (a) displacement input amplitude $=20 \mathrm{~mm}$ and frequency $=0.1 \mathrm{~Hz}$; $(\mathrm{b})$ amplitude $=10 \mathrm{~mm}$ and frequency $=3 \mathrm{~Hz}$; (c) amplitude $=7 \mathrm{~mm}$ and frequency $=5 \mathrm{~Hz}$; (d) amplitude $=1.5 \mathrm{~mm}$ and frequency $=10 \mathrm{~Hz}$.

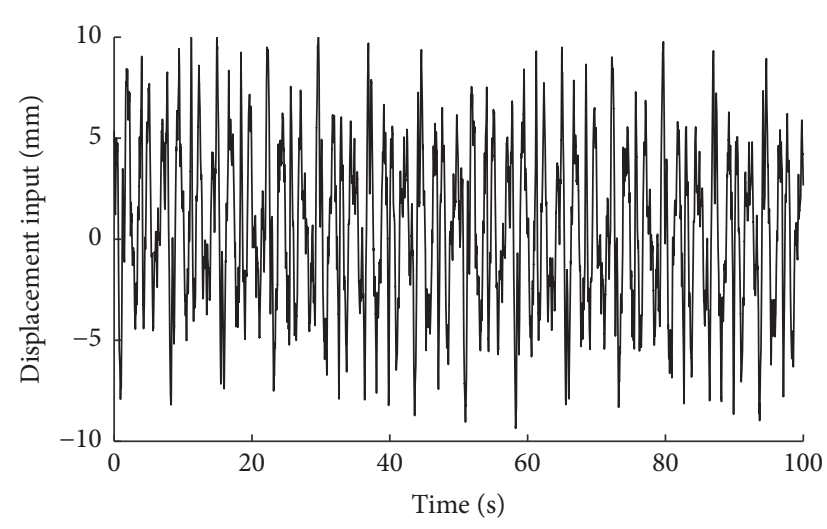

(a)

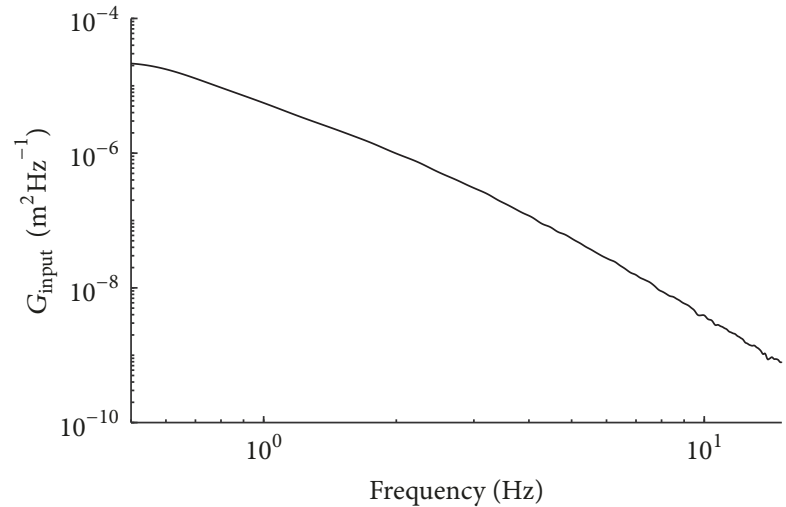

(b)

FIGURE 15: Random input: (a) input signal and (b) power spectrum density of input signal. 

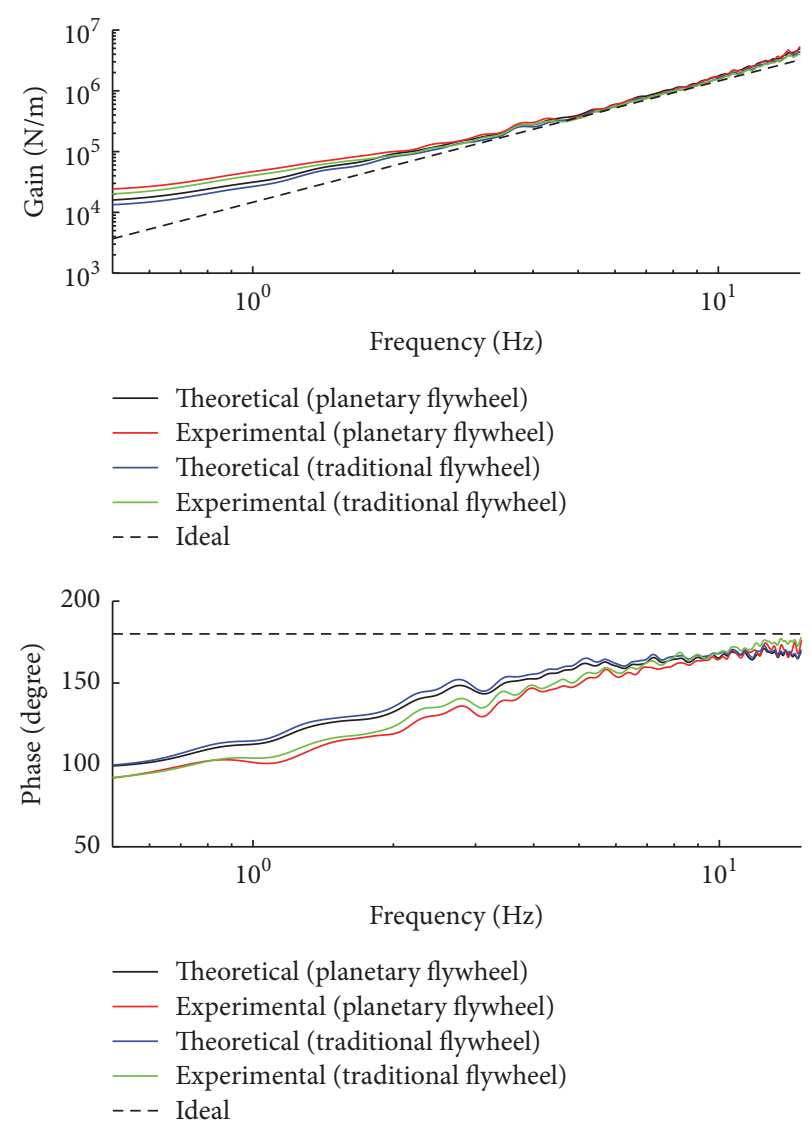

FIGURE 16: Frequency response of the inerters.

accuracy of the model. When the frequency is low, the amplitude of the model is smaller than that of the experiment. This is mainly because the impact of friction on the output force is relatively large at low frequency, but the friction model is only a theoretical approximation to the friction phenomenon. In general, the change of model output with frequency was consistent with that of the experiment data, which proves the model's validity of being used in the investigation and design work on mechanical network.

Literature [18] gives the response of the ball screw inerter and the rack-pinion inerter with traditional flywheel. When excited at a frequency of $0.1 \mathrm{~Hz}$, the output force of the rackpinion inerter is a triangular wave with large fluctuating, and the output force of the ball screw inerter is similar to a square wave. Although the ball screw inerter with planetary flywheel and the rack-pinion inerter both use gear mechanisms, their dynamic characteristics are quite different. This is because, for the rack-pinion inerter, the conversion of the linear motion to the rotational motion is accomplished by the rack and pinion. The gear backlash will cause the output force of the inerter to have a greater fluctuation. For the planetary flywheel inerter, the conversion of the linear motion to the rotational motion is accomplished by the ball screw which can be preloaded and the simultaneous engagement of multiple planetary gears produces an average effect on the fluctuation of the output force. The gear backlash has little effect on the output force of the planetary flywheel inerter. The dynamic performance of the ball screw inerter with planetary flywheel is similar to that of the ball screw inerter with traditional flywheel. In addition, the ball screw inerter has a greater inertia-to-mass ratio than the rack-pinion inerter. The planetary flywheel inerter can reduce the flywheel weight more effectively. The rack-pinion inerter is more suitable for the applications where the flywheel cannot be mounted on the inerter axis due to space constraints.

As presented in Figures 13-16, the inerter's dynamic characteristics of the planetary flywheel type and the traditional flywheel type are basically the same, indicating that the planetary flywheel can be the core inertial component of an inerter and be a replacement of the traditional flywheel.

\section{Conclusion}

(1) In this paper, we propose the planetary flywheel inerter as a new structural type of inerters. When a relative movement occurs between the two terminals of the inerter, the planetary flywheel produces a compound screw-driven motion composed of revolving and rotating. The torque of the flywheel is proportional to the rotational acceleration of the screw. Therefore, the output force is proportional to the relative linear acceleration between the inerter's two terminals. In other words, the planetary flywheel inerter is compatible with the mechanical output requirements of an ideal inerter. 
(2) A nonlinear dynamical model of the planetary flywheel inerter is established by theoretical analysis. Based on the model parameter identification, the response characteristics of the model shows remarkable agreement with the experimental data, which proves the model's validity of being used in the investigation and design work on mechanical network.

(3) The dynamical transfer characteristics of the planetary flywheel inerter and that of the traditional flywheel inerter are basically the same. However, the former's transmissibility is slightly larger than that of the latter in low-frequency range due to the friction torque of the planetary gears.

(4) The planetary flywheel can be a good substitute for the traditional flywheel. While the same inertance is accomplished, the mass of a planetary flywheel is notably less than a traditional flywheel with the same outer diameter, which helps to make the inerter lightweight.

\section{Conflicts of Interest}

The authors declare that there are no conflicts of interest regarding the publication of this paper.

\section{Acknowledgments}

This work was supported in part by the National Natural Science Foundation of China (Grant no. 51005206).

\section{References}

[1] M. Z. Q. Chen, C. Papageorgiou, F. Scheibe, F.-C. Wang, and M. Smith, "The missing mechanical circuit element," IEEE Circuits and Systems Magazine, vol. 9, no. 1, pp. 10-26, 2009.

[2] M. C. Smith, "Synthesis of mechanical networks: the inerter," Institute of Electrical and Electronics Engineers Transactions on Automatic Control, vol. 47, no. 10, pp. 1648-1662, 2002.

[3] C. Li, M. Liang, Y. Wang, and Y. Dong, "Vibration suppression using two-terminal flywheel. Part I: Modeling and characterization," Journal of Vibration and Control, vol. 18, no. 8, pp. 10961105, 2011.

[4] Y. Shen, L. Chen, X. Yang, D. Shi, and J. Yang, "Improved design of dynamic vibration absorber by using the inerter and its application in vehicle suspension," Journal of Sound and Vibration, vol. 361, pp. 148-158, 2016.

[5] M. Z. Q. Chen, K. Wang, C. Li, and G. Chen, "Realizations of biquadratic impedances as five-element bridge networks containing one inductor and one capacitor," in Proceedings of the 33rd Chinese Control Conference, CCC 2014, pp. 7498-7503, Nanjing, China, July 2014.

[6] M. Z. Q. Chen, K. Wang, Y. Zou, and J. Lam, "Realization of a special class of admittances with one damper and one inerter for mechanical control," Institute of Electrical and Electronics Engineers Transactions on Automatic Control, vol. 58, no. 7, pp. 1841-1846, 2013.

[7] K. Wang, M. Z. Q. Chen, and Y. Hu, "Synthesis of biquadratic impedances with at most four passive elements," Journal of The Franklin Institute, vol. 351, no. 3, pp. 1251-1267, 2014.

[8] T.-T. Tran and H. Hasegawa, "Advanced Passive Suspension with Inerter Devices and Optimization Design for Vehicle
Oscillation," International Journal of Mechanical Engineering and Robotics Research, vol. 4, no. 4, pp. 354-360, 2015.

[9] Y. L. Hu, M. Z. Q. Chen, and Z. Shu, "Passive vehicle suspensions employing inerters with multiple performance requirements," Journal of Sound and Vibration, vol. 333, no. 8, pp. 2212-2225, 2014.

[10] F.-C. Wang, M.-F. Hong, and C.-W. Chen, "Building suspensions with inerters," Proceedings of the Institution of Mechanical Engineers, Part C: Journal of Mechanical Engineering Science, vol. 224, no. 8, pp. 1605-1616, 2010.

[11] Y. Hanazawa, H. Suda, and M. Yamakita, "Analysis and experiment of flat-footed passive dynamic walker with ankle inerter," in Proceedings of the 2011 IEEE International Conference on Robotics and Biomimetics, ROBIO 2011, pp. 86-91, Phuket, Thailand, December 2011.

[12] S. Evangelou, D. J. N. Limebeer, R. S. Sharp, and M. C. Smith, "Control of motorcycle steering instabilities: Passive mechanical compensators incorporating inerters," IEEE Control Systems Magazine, vol. 26, no. 5, pp. 78-88, 2006.

[13] M. C. Smith and F.-C. Wang, "Performance benefits in passive vehicle suspensions employing inerters," Vehicle System Dynamics, vol. 42, no. 4, pp. 235-257, 2004.

[14] F.-C. Wang, M.-F. Hong, and T.-C. Lin, "Designing and testing a hydraulic inerter," Proceedings of the Institution of Mechanical Engineers, Part C: Journal of Mechanical Engineering Science, vol. 225, no. 1, pp. 66-72, 2011.

[15] Y. Shen, L. Chen, Y. Liu, and X. Zhang, "Modeling and Optimization of Vehicle Suspension Employing a Nonlinear Fluid Inerter," Shock and Vibration, vol. 2016, Article ID 2623017, 2016.

[16] S. J. Swift, M. C. Smith, A. R. Glover, C. Papageorgiou, B. Gartner, and N. E. Houghton, "Design and modelling of a fluid inerter," International Journal of Control, vol. 86, no. 11, pp. 2035-2051, 2013.

[17] F.-C. Wang and H.-A. Chan, "Vehicle suspensions with a mechatronic network strut," Vehicle System Dynamics, vol. 49, no. 5, pp. 811-830, 2011.

[18] C. Papageorgiou and M. C. Smith, "Laboratory experimental testing of inerters," in Proceedings of the 44th IEEE Conference on Decision and Control, and the European Control Conference, pp. 3351-3356, Seville, Spain, December 2005.

[19] Y. Hu, M. Z. Q. Chen, S. Xu, and Y. Liu, "Semiactive Inerter and Its Application in Adaptive Tuned Vibration Absorbers," IEEE Transactions on Control Systems Technology, vol. 25, no. 1, pp. 294-300, 2017.

[20] L. Pires, M. C. Smith, N. E. Houghton, and R. A. McMahon, "Design trade-offs for energy regeneration and control in vehicle suspensions," International Journal of Control, vol. 86, no. 11, pp. 2022-2034, 2013.

[21] X. Q. Sun, L. Chen, S. H. Wang, X. L. Zhang, and X. F. Yang, "Performance investigation of vehicle suspension system with nonlinear ball-screw inerter," International Journal of Automotive Technology, vol. 17, no. 3, pp. 399-408, 2016.

[22] A. Gonzalez-Buelga, I. F. Lazar, J. Z. Jiang, S. A. Neild, and D. J. Inman, "Assessing the effect of nonlinearities on the performance of a tuned inerter damper," Structural Control and Health Monitoring, vol. 24, no. 3, Article ID e1879, 2017.

[23] S. Yang, T. Xu, C. Li, M. Liang, and N. Baddour, "Design, Modeling and Testing of a Two-Terminal Mass Device With a Variable Inertia Flywheel," Journal of Mechanical Design, vol. 138, no. 9, Article ID 095001, 2016. 
[24] R. Faraj, J. Holnicki-Szulc, L. Knap, and J. Seńko, "Adaptive inertial shock-absorber," Smart Materials and Structures, vol. 25, no. 3, Article ID 035031, 2016.

[25] P. Brzeski, T. Kapitaniak, and P. Perlikowski, "Novel type of tuned mass damper with inerter which enables changes of inertance," Journal of Sound and Vibration, vol. 349, pp. 56-66, 2014.

[26] F.-C. Wang and W.-J. Su, "Inerter nonlinearities and the impact on suspension control," in Proceedings of the 2008 American Control Conference, ACC, pp. 3245-3250, Washington, wash, USA, June 2008.

[27] A. Kahraman, "Natural modes of planetary gear trains," Journal of Sound and Vibration, vol. 173, no. 1, pp. 125-130, 1994.

[28] M. Nordin, J. Galic', and P.-O. Gutman, "New models for backlash and gear play," International Journal of Adaptive Control and Signal Processing, vol. 11, no. 1, pp. 49-63, 1997.

[29] L. Márton and B. Lantos, "Control of mechanical systems with Stribeck friction and backlash," Systems \& Control Letters, vol. 58, no. 2, pp. 141-147, 2009. 


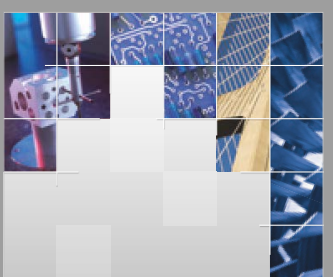

\section{Enfincering}
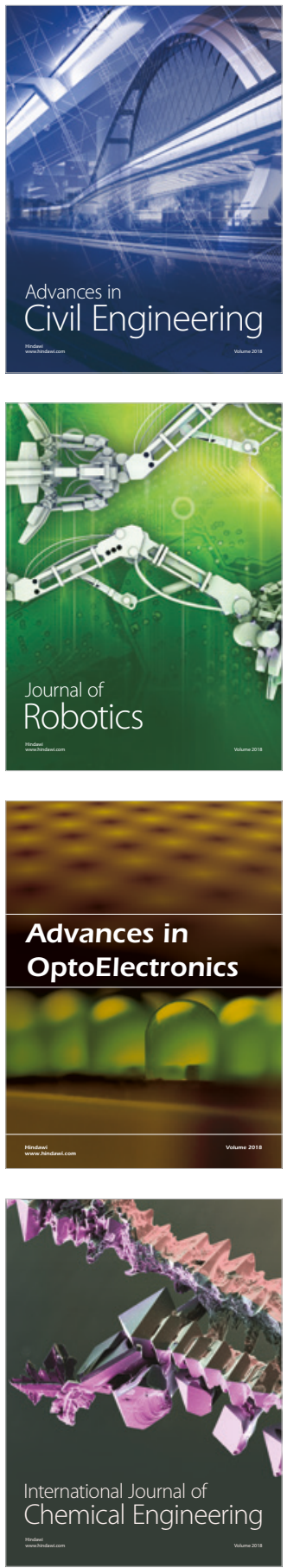

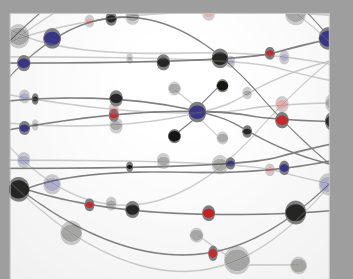

\section{Rotating \\ Machinery}

The Scientific World Journal

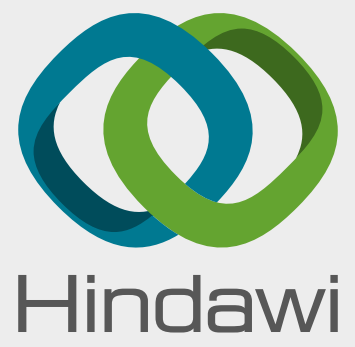

Submit your manuscripts at

www.hindawi.com
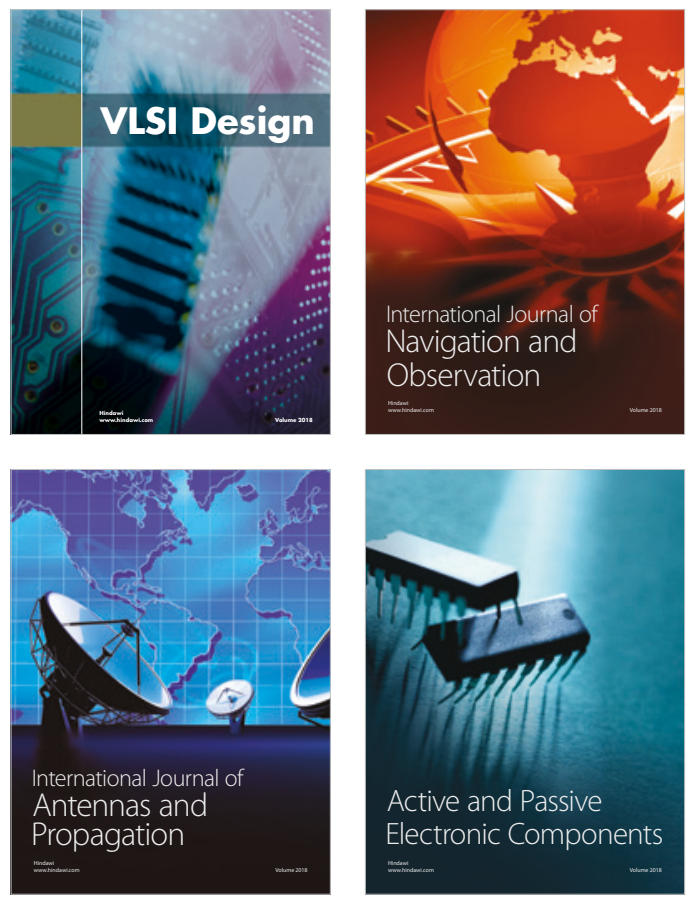
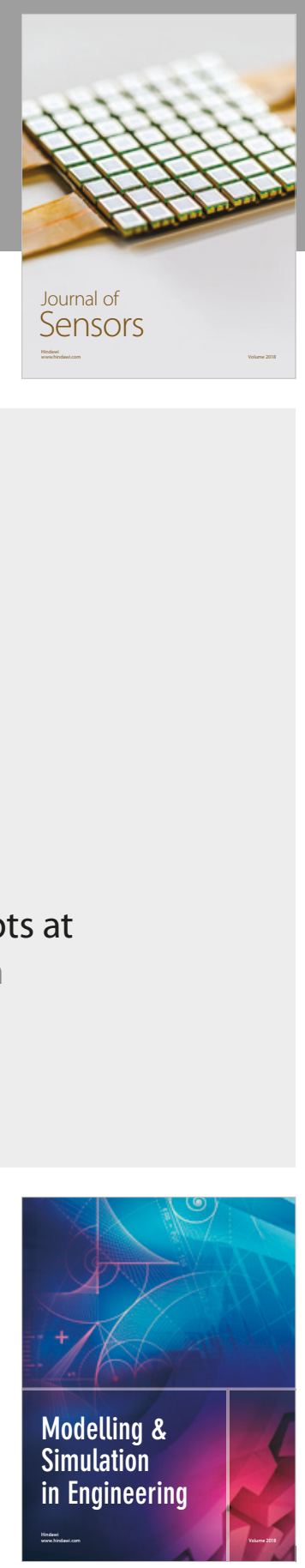

\section{Advances \\ Multimedia}
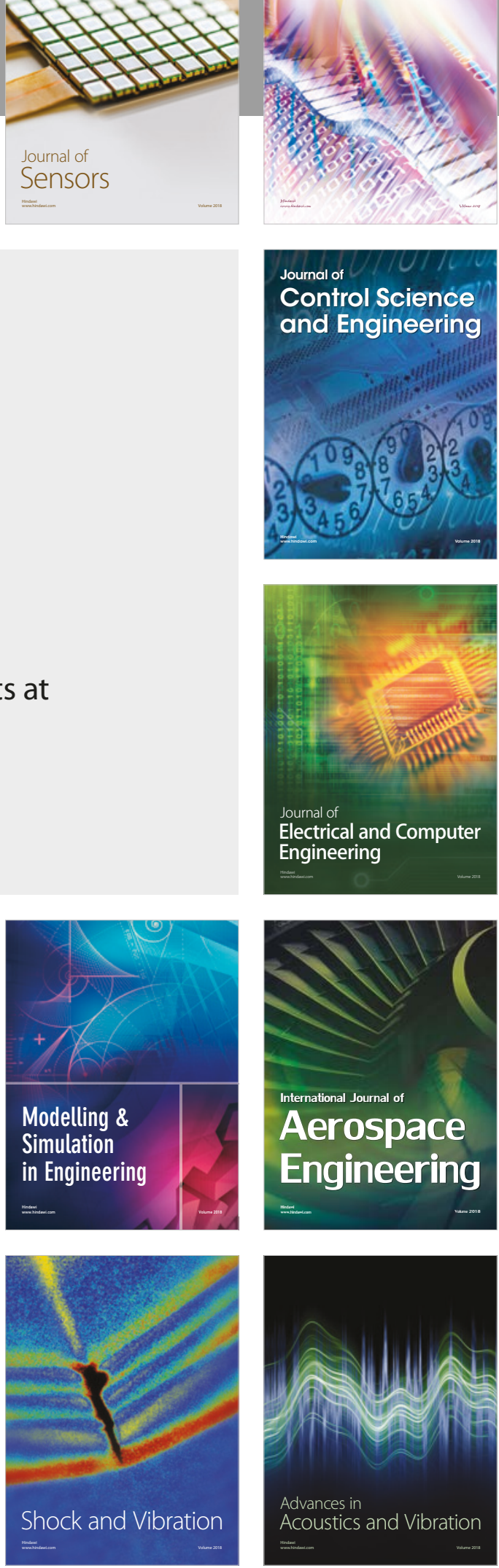